\title{
HEALTH LITERACY AND MEDICATION ADHERENCE IN FIBROMYALGIA
}

Meliha KASAPOGLU AKSOY ${ }^{1}$, Hakan DEMIRCI ${ }^{2}$, Ilknur AYKURT KARLIBEL ${ }^{1}$, Koray AYAR ${ }^{3}$, Deniz AZKAN TURE ${ }^{2}$, Lale ALTAN ${ }^{4}$

${ }^{1}$ Department of Physical Medicine and Rehabilitation, University of Health Sciences Turkey Bursa Yuksek Ihtisas Training and Research Hospital, Bursa, TURKEY

${ }^{2}$ Department of Family Medicine, University of Health Sciences Turkey Bursa Yuksek Ihtisas Training and Research Hospital, Bursa, TURKEY

${ }^{3}$ Department of Romatology, University of Health Sciences Turkey Bursa Yuksek Ihtisas Training and Research Hospital, Bursa, TURKEY

${ }^{4}$ Department of Physical Medicine and Rehabilitation, Medica Faculty, Uludag University, Bursa, TURKEY

\section{ABSTRACT}

Aim: Patients with fibromyalgia syndrome (FMS) are reported to be 3 times more likely to use health care services compared to the general population, 4 times more likely to go to the doctor, have 4 times more drug use and 2.5 times more pain-related expenditures. In this study, we firstly aimed to investigate the relationship between health literacy $(\mathrm{HL})$ and medication adherence (MA) in FMS patients who were treated for at least six months. Secondly, we planned to investigate the association of $\mathrm{HL}$ with disease activity.

Methods: This study had a cross-sectional analytical design. Patients diagnosed with FMS according to the 2014 ACR diagnostic criteria for at least six months were included in the study. Visual Analog Scale (VAS), fibromyalgia impact questionnaire (FIQ), The European Health Literacy Survey Questionnaire (HLSEU-Q47) and the Morisky 8-Item MA scale forms were filled out in face-to-face interviews with the patients.

Results: The study was completed with a total of $142 \mathrm{FMS}$ patients. There was a statistically significant difference between the Morisky 8-Item MA groups according to the HLS-EU-Q47 scale and sub-scale scores $(p<0.05)$. There was also a difference between the Morisky 8-Item MA groups according to the health service score. There was a negative significant correlation between the Morisky 8-Item MA scale score and VAS measurements.

Conclusions: We believe that educational programs for patients about FMS and increasing their MA and $\mathrm{HL}$ will positively affect their treatment outcomes.

Keywords: Health literacy, HLS-EU-Q47, fibromyalgia syndrome, medication adherence, VAS

Corresponding Author: Meliha KASAPOGLU AKSOY melihakasapoglu@hotmail.com

Received: April 18, 2021; Accepted: April 22, 2021; Published Online: April 23, 2021

Cite this article as: Kasapoglu Aksoy, M., Demirci, H., Aykurt Karlibel, I., Ayar, K., Azkan Ture, D. \& Altan, L. (2021). Health Literacy and Medication Adherence in Fibromyalgia. European Health Literacy Journal 1(1), 1-11. 


\section{Introduction}

Fibromyalgia Syndrome (FMS) is a chronic disease characterized by widespread pain of unknown origin, fatigue, sleep disturbances, cognitive dysfunction and generalized tenderness in the body [1]. The prevalence of illness among patients, the majority of whom are female, is reported to be $0.66-1.5 \%$ in the general population [2]. The prevalence in women between 20 and 74 years of age has been found to be $3.6 \%$ in Turkey [3]. Although the etiology of FMS is still uncertain, it is suggested that the main mechanism is central sensitization and that genetic, immunological and hormonal factors also play an important role [4]. According to EULAR recommendations, non-pharmacological and pharmacological treatments are applied in a multidisciplinary manner in FMS treatment [5]. Pharmacological agents with proven efficacy in FMS are tricyclic antidepressants (TSA), tramadol, serotonin-norepinephrine reuptake inhibitors (SNRI), selective serotonin reuptake inhibitors (SSRI) and anticonvulsants (pregabalin and gabapentin) $[5,6]$. Patients with FMS are reported to be 3 times more likely to use health care services compared to the general population, 4 times more likely to go to the doctor, have 4 times more drug use and 2.5 times more pain-related expenditures [7].

Health literacy $(\mathrm{HL})$ can be defined as the ability of a patient to understand, interpret and behave accordingly when medical information is presented to the patient [8]. It has been shown that $\mathrm{HL}$ is related to a health seeking behavior [9]. It has been stated that patients with insufficient HL seek a solution in coming to the emergency services while patients with sufficient HL present to the relevant specialists [10]. Chronic diseases such as FMS are an extra burden for both governments and health care professionals
$[11,12]$. It is argued that societies with better $\mathrm{HL}$ use health care services more efficiently [13].

The most important factor that plays a role in the efficacy of treatment is patient medication adherence. Medication adherence (MA) is the extent to which the behavior of the patient coincides with clinical advice, such as using medications, following a diet, exercising or performing other lifestyle changes. Non-adherence may start with not adhering to the drug treatment, not having the prescription written, or not following the recommended program [14]. Medication adherence reduces relapses. HL affects medication adherence positively [15]. Although there are a limited number of studies with rheumatologic diseases, $\mathrm{HL}$ affects the success of treatment in chronic diseases [16-20]. It has been shown that $\mathrm{HL}$ is associated with insulin doses used in DM patients [21]. Similarly, there is a positive correlation between the type and dose of drugs used in COPD patients. Adequate HL affects both drug costs and patient quality of life positively [22].

In this study, we firstly aimed to investigate the relationship between $\mathrm{HL}$ and medication adherence in FMS patients who were treated for at least six months. Secondly, we planned to investigate the association of HL with disease activity.

\section{METHOD}

\section{Study Design}

This study had a cross-sectional analytical design. Data of 200 patients were evaluated. The patients were diagnosed with FMS according to the 2014 ACR diagnostic criteria for at least six months in the Physical Therapy and Rehabilitation and Rheumatology Clinics of the University of Health Sciences Bursa Training and Research Hospital and were using medication between April 2017 and September 2017. Detailed information was given to 
the patients before the study, and their written informed consent was obtained afterwards. Our work was carried out in accordance with the World Declaration of Helsinki. The local ethics committee of the hospital approved the study.

\section{Participants}

Patients who were older than 18 years of age and who were able to read and write were included in the study. Patients who did not want to participate in the questionnaire or who were illiterate were not included in the study. Demographic data of the patients were recorded. Of the 200 patients, 43 patients were excluded because they responded to the questionnaire inadequately, and 15 patients were excluded from the study because they did not agree to participate in the study.

\section{Interventions}

Visual Analog Scale (VAS): VAS was used to determine the severity of pain and fatigue of the patients. Numbers from 0 to 10 on a $10-\mathrm{cm}$ line in the VAS were described to the patients [23].

Fibromyalgia Impact Questionnaire (FIQ): This form was developed by Burchardt et al. [24] to measure functional status in FMS patients and adapted in terms of validity and reliability specific to Turkey by Sarmer et al. [25].

\section{The European Health Literacy Survey \\ Questionnaire (HLS-EU-Q47): The scale was} developed in 2011 [8] and the Turkish validity and reliability of the scale was determined by Tanrıver et al. [26].

\section{The Morisky 8- Item Medication Adherence}

Scale: The Morisky 8-Item Medication Adherence Scale was used for medication adherence [27]. It was translated into Turkish and validated by Asilar et al. $[28,29]$.

\section{Statistical analysis}

A post hoc power analysis was conducted using a moderate effect size, based upon findings of the present study. A moderate effect size was obtained by comparing overall health literacy scale points between medical adherence groups. Using this effect size $(r=0.49)$ with a sample size of 142 participants, the power was estimated to be 0.81 at a significance level of $a=0.05$. The normal distribution of variables was examined by Shapiro Wilk test. Continuous variables are expressed as median (minimum: maximum) values. Categorical variables are expressed as percentage $\mathrm{n}(\%)$. Kruskal Wallis test was used in the comparison between normative test results, between groups determined according to the HLS-EU scale and subscale scores, and comparison between related scores and medication groups. The Fisher-FreemanHalton test was used in comparisons between drug groups according to drug compliance. Scores of the HLS-EU scale and subscales and scores of the Morisky 8 Item MA scale were examined by correlation analysis between FIQ total and VAS measures and reported by Spearman correlation coefficient. The internal consistency of the HLS-EU scale was examined by Cronbach alpha coefficient. Data analysis was performed with SPSS (IBM Corp. Released 2012. IBM SPSS Statistics for Windows, Version 21.0. Armonk, NY: IBM Corp.). Values of $p<0.05$ were accepted as significant

\section{RESULTS}

The study was completed with a total of 142 FMS patients. The mean age of the patients was calculated as $46.62 \pm 11.50$. The socio-demographic characteristics of the participants are given in Table 1. 

Table1. The socio-demographic characteristics and evaluation parameters of the participants

\begin{tabular}{|c|c|}
\hline Gender(Female/Male) & $138(\% 97) / 4(\% 3)$ \\
\hline Age (year) & $46.62 \pm 11.50(22: 86)$ \\
\hline \multicolumn{2}{|l|}{ Age Groups } \\
\hline $20-29$ & $7(\% 4.90)$ \\
\hline $30-39$ & $33(\% 23.20)$ \\
\hline $40-49$ & $53(\% 37.30)$ \\
\hline $50-59$ & $31(\% 21.80)$ \\
\hline$>60$ & $18(\% 12.70)$ \\
\hline \multicolumn{2}{|l|}{ Marital status } \\
\hline single & $10(\% 7.04)$ \\
\hline married & $114(\% 80.30)$ \\
\hline widow & $18(\% 12.66)$ \\
\hline \multicolumn{2}{|l|}{ Employment status } \\
\hline Not working & $10(\% 7.04)$ \\
\hline housewife & $80(\% 56.33)$ \\
\hline worker & $15(\% 10.56)$ \\
\hline retired & $15(\% 10.56)$ \\
\hline Professional occupation & $22(\% 15.49)$ \\
\hline \multicolumn{2}{|l|}{ Educational level } \\
\hline No school education & $17(\% 11.97)$ \\
\hline Primary school & $75(\% 52.80)$ \\
\hline High school & $19(\% 13.40)$ \\
\hline University & $24(\% 16.90)$ \\
\hline HLS-EU-total & $27.47 \pm 7.34(7.20-48.23)$ \\
\hline HLS-EU-Health Care & $29.62 \pm 7.29(5.21-48.96)$ \\
\hline HLS-EU-Disease Prevention & $26.67 \pm 8.44(3.85-50.00)$ \\
\hline HLS-EU-Health Promotion & $29.03 \pm 8.07(7.29-50.00)$ \\
\hline The Morisky 8- Item Medication Adherence Scale & $4.86 \pm 2.38(0-8)$ \\
\hline VAS & $6.7 \pm 2.0(1-9)$ \\
\hline FIQ-Total) & $56.94 \pm 17.34(20.24-91.68)$ \\
\hline
\end{tabular}

HLS-EU: The European Health Literacy Survey Questionnaire FIQ: Fibromyalgia Impact

Ouestionnaire VAS: Visual Analog Scale mean \pm standard deviation (min-max) and percentages are given 
relationship between the obtained data and HLS-EUQ47 is given in Table 2. There was a statistically significant difference between the Morisky 8 Item MA groups according to the HLS-EU-Q47 scale and subscale scores $(p<0.05)$.

Table2. Comparison of HLS-EU scores among Morisky 8-Item Medication Adherence Score

\begin{tabular}{|c|c|c|c|c|}
\hline \multirow[b]{2}{*}{ HLS-EU Score } & \multicolumn{3}{|c|}{ The Morisky 8- Item Medication Adherence Scale Score } & \multirow[b]{2}{*}{ p-value } \\
\hline & $\begin{array}{l}\text { Low adherence } \\
(n=79)\end{array}$ & $\begin{array}{l}\text { Moderate adherence } \\
(\mathrm{n}=\mathbf{4 0})\end{array}$ & $\begin{array}{l}\text { High adherence } \\
(\mathbf{n}=\mathbf{2 3})\end{array}$ & \\
\hline $\begin{array}{l}\text { Health Care } \\
\text { (Q1-16) }\end{array}$ & $29.17(5.21: 46.88)$ & $31.25(17.71: 43.33)$ & $31.25(21.88: 48.96)$ & $0.005^{\mathrm{a}}$ \\
\hline $\begin{array}{l}\text { Disease Prevention } \\
\text { (Q17-31) }\end{array}$ & $26.67(3.75: 50)$ & 31.11(14.44:42.86) & 28.89(12.22:42.22) & $0.034^{a}$ \\
\hline $\begin{array}{l}\text { Health Promotion } \\
(\text { Q32-47) }\end{array}$ & $23.95(7.29: 50)$ & $29.17(7.78: 43.75)$ & 29.17(14.58:42.71) & $0.040^{a}$ \\
\hline $\begin{array}{l}\text { Total } \\
\text { (Q1-47) }\end{array}$ & 26.95(7.20:48.23) & 30.67(15.91:43.33) & 29.43(16.31:42.55) & $0.009^{\mathrm{a}}$ \\
\hline
\end{tabular}

The values were given as median (minimum:maximum); a: Kruskal Wallis testi, HLS-EU: The European Health Literacy Survey Questionnaire

There was a difference between the Morisky 8 Item MA groups according to the health service score. In the analysis of subgroups, it was determined that the scale scores in the groups with high and moderate MA were higher than those with low MA $(p<0.05)$.

There was a statistically significant difference between the MA groups according to the disease prevention score. When the subgroups were analyzed, it was determined that the scale scores in the group with moderate MA was higher than those with low MA $(p=0.018)$.

There was a difference between the MA groups according to the health promotion score. In the analysis of subgroups, it was determined that the scale scores in the group with moderate MA were higher than those with low MA $(p=0.025)$.

There was a difference between the MA groups according to the overall scale score. In the subgroup analyses, it was determined that the scale scores in the groups with high and moderate MA were higher than those with low MA $(p=0.050$ and $p=0.005$, respectively).

$62 \%$ of the participants $(n=88)$ used only duloxetine, $15.5 \%(n=22)$ used only pregabalin, 9.2\% $(n=13)$ used both duloxetine and pregabalin, and $13.3 \%(n=19)$ of the patients used other treatments. The distribution of the scale scores according to the drugs used by the patients is given in Table 3 . There was no difference between the drug groups according to the HLS-EU sub-scales and overall scale scores. 
There was no difference according to the MA level among the drug groups. There was no difference between the drug groups according to the FIQ total and VAS measurements.

Table3. Relationship between FIQ total score, VAS measures and Health literacy and Morisky 8 Item medication adherence scores

\begin{tabular}{|c|c|c|c|}
\hline & & FIQ Total & VAS \\
\hline \multirow{2}{*}{$\begin{array}{l}\text { HLS-EU } \\
\text { Health Care }\end{array}$} & $\mathrm{r}$ & -0.21 & -0.25 \\
\hline & $\mathrm{p}$ & 0.016 & 0.003 \\
\hline \multirow{2}{*}{$\begin{array}{l}\text { HLS-EU } \\
\text { Disease Prevention }\end{array}$} & $\mathrm{r}$ & -0.16 & -0.24 \\
\hline & $\mathrm{p}$ & 0.073 & 0.004 \\
\hline \multirow{2}{*}{$\begin{array}{l}\text { HLS-EU } \\
\text { Health Promotion }\end{array}$} & $\mathrm{r}$ & -0.26 & -0.27 \\
\hline & $\mathrm{p}$ & 0.003 & 0.001 \\
\hline \multirow{2}{*}{$\begin{array}{l}\text { HLS-EU } \\
\text { Total }\end{array}$} & $\mathrm{r}$ & -0.22 & -0.27 \\
\hline & $\mathrm{p}$ & 0.012 & 0.001 \\
\hline \multirow[t]{2}{*}{ Morisky 8-Item medication adherence } & $\mathrm{r}$ & -0.17 & -0.25 \\
\hline & $\mathrm{p}$ & 0.051 & 0.003 \\
\hline
\end{tabular}

HLS-EU: The European Health Literacy Survey Questionnaire FIQ: Fibromyalgia Impact

Questionnaire VAS: Visual Analog Scale r: Spearman correlation coefficient

The relationships between the HLS-EU-Q47 and FIQ are shown in Table 4. There was a negative correlation between the health service score and the FIQ Total and VAS pain score. The increases observed in the FIQ Total and VAS measurements led to a decrease in health service scores. There was a negative correlation between the disease prevention score and VAS measurements. The increases observed in the VAS measurements led to a decrease in the disease prevention score. There was a negative correlation between the health promotion score and the FIQ Total and VAS measurements. The increases observed in the
FIQ Total and VAS measurements led to a decrease in the health promotion score. There was a negative correlation between the overall scale score and the FIQ Total and VAS measurements. The increases observed in the FIQ Total and VAS measurements led to a decrease in the overall scale score. There was no relationship between the HLS-EU-Q47 sub-scale and overall scale scores. There was a negative significant correlation between the Morisky 8 Item MA scale score and the VAS measurements. The increases observed in the VAS measurements led to a decrease in the Morisky 8 Item MA scale score. There was no relationship between the Morisky 8 Item MA scale score and the FIQ Total. 
Table4. Comparison of HLS-EU scores, Morisky 8 Item medication adherences scores and treatment related measures between drug groups

\begin{tabular}{|c|c|c|c|c|c|}
\hline & \multicolumn{4}{|c|}{ Medication groups } & \multirow[b]{2}{*}{ p-value } \\
\hline & Duloksetin & Pregabalin & $\begin{array}{l}\text { Duloksetin } \\
\& \\
\text { Pregabalin }\end{array}$ & Other medication & \\
\hline HLS-EU-Health Care & $\begin{array}{l}30,21 \\
(5.21: 43.75)\end{array}$ & $\begin{array}{l}30,73 \\
(7.78: 48.96)\end{array}$ & $\begin{array}{l}28,13 \\
(21.88: 43.33)\end{array}$ & $\begin{array}{l}29,17 \\
(18.75: 46.88)\end{array}$ & $0.471^{\mathrm{a}}$ \\
\hline $\begin{array}{l}\text { HLS-EU } \\
\text { Disease Prevention }\end{array}$ & $\begin{array}{l}27,78 \\
(6.77: 44.44)\end{array}$ & $\begin{array}{l}27,23 \\
(3.85: 50)\end{array}$ & $\begin{array}{l}26,67 \\
(17.78: 42.86)\end{array}$ & $\begin{array}{l}28,89 \\
(13.33: 50)\end{array}$ & $0.865^{\mathrm{a}}$ \\
\hline $\begin{array}{l}\text { HLS-EU } \\
\text { Health Promotion }\end{array}$ & $\begin{array}{l}27,95 \\
(7.29: 41.67)\end{array}$ & $\begin{array}{l}24,20 \\
(7.78: 50)\end{array}$ & $\begin{array}{l}23,96 \\
(15.63: 43.75)\end{array}$ & $\begin{array}{l}28,13 \\
(10.42: 45.83)\end{array}$ & $0.912^{\mathrm{a}}$ \\
\hline $\begin{array}{l}\text { HLS-EU } \\
\text { Total }\end{array}$ & $\begin{array}{l}28,37 \\
(9.57: 39.01)\end{array}$ & $\begin{array}{l}26,06 \\
(7.20: 48.23)\end{array}$ & $\begin{array}{l}28,13 \\
(10.42: 45.83)\end{array}$ & $\begin{array}{l}29,71 \\
(15.60: 47.52)\end{array}$ & $0.902^{\mathrm{a}}$ \\
\hline Morisky scale & & & & & \\
\hline Low adherence & $48(\% 54.50)$ & $9(\% 40.90)$ & $7(\% 53.80)$ & $15(\% 78.90)$ & \\
\hline Moderate adherence & $25(\% 28.40)$ & $9(\% 40.90)$ & $3(\% 23.10)$ & $3(\% 15.80)$ & $0.326^{\mathrm{b}}$ \\
\hline High Adherence & $15(\% 17)$ & $4(\% 18.20)$ & $3(\% 23.10)$ & $1(\% 5.30)$ & \\
\hline FIQ Total & $\begin{array}{l}58,16 \\
(24,27: 91.52)\end{array}$ & $\begin{array}{l}56,12 \\
(22.06: 91.68)\end{array}$ & $\begin{array}{l}51,23 \\
(32.49: 82.14)\end{array}$ & $\begin{array}{l}54,82 \\
(20.24: 90.77)\end{array}$ & $0.726^{\mathrm{a}}$ \\
\hline VAS & $\begin{array}{l}23,75 \\
(2: 50)\end{array}$ & $\begin{array}{l}20,75 \\
(9: 41.50)\end{array}$ & $\begin{array}{l}22,50 \\
(14: 34)\end{array}$ & $\begin{array}{l}23 \\
(9: 43)\end{array}$ & $0.919^{\mathrm{a}}$ \\
\hline
\end{tabular}

Values given as median(minimum-maximum), $n(\%)$ percentage; a: Kruskal Wallis test, b: Fisher-Freeman-Halton test HLS-EU: The European Health Literacy Survey Questionnaire, Morisky Scale: The Morisky 8-Item Medication Adherence Scale, FIQ: Fibromyalgia Impact Questionnaire, VAS: Visual Analog Scale.

Internal reliability coefficients of the HLS-EU-Q47 and Morisky 8 Item MA scale score are given in Table 5. The internal reliability coefficients were found to be sufficient for both scales. Reliability coefficients of the HLS-EU-Q47 scale and subscales: $a=0.885$ for health care, $a=0.911$ for disease prevention, $a=0.911$ for health reduction and $a=0.965$ for general health. The internal consistency of the Morisky 8 Item MA scale compliance score was calculated using the KuderRichardson 20 Test (KR-20) coefficient and the reliability coefficient was calculated as KR20 $=0.767$. 
Table5. General Health Literacy and Sub Indexes and Morisky 8-Item Medication Adherence Internal Reliability Coefficients

\begin{tabular}{|l|l|}
\hline $\begin{array}{l}\text { HLS-EU } \\
\text { Health Care }\end{array}$ & Cronbach's alfa or KR=20 \\
\hline $\begin{array}{l}\text { HLS-EU } \\
\text { Disease Prevention }\end{array}$ & $\alpha=0.965$ \\
\hline $\begin{array}{l}\text { HLS-EU } \\
\text { Health Promotion }\end{array}$ & $\alpha=0.915$ \\
\hline $\begin{array}{l}\text { HLE-EU } \\
\text { Total }\end{array}$ & $\alpha=0.911$ \\
\hline Morisky 8-Item medication adherence & $\mathrm{KR}_{20}=0.767$ \\
\hline
\end{tabular}

HLS-EU: The European Health Literacy Survey Questionnaire

Figure 1 shows the relationship between medication adherence to fibromyalgia drugs and health literacy.

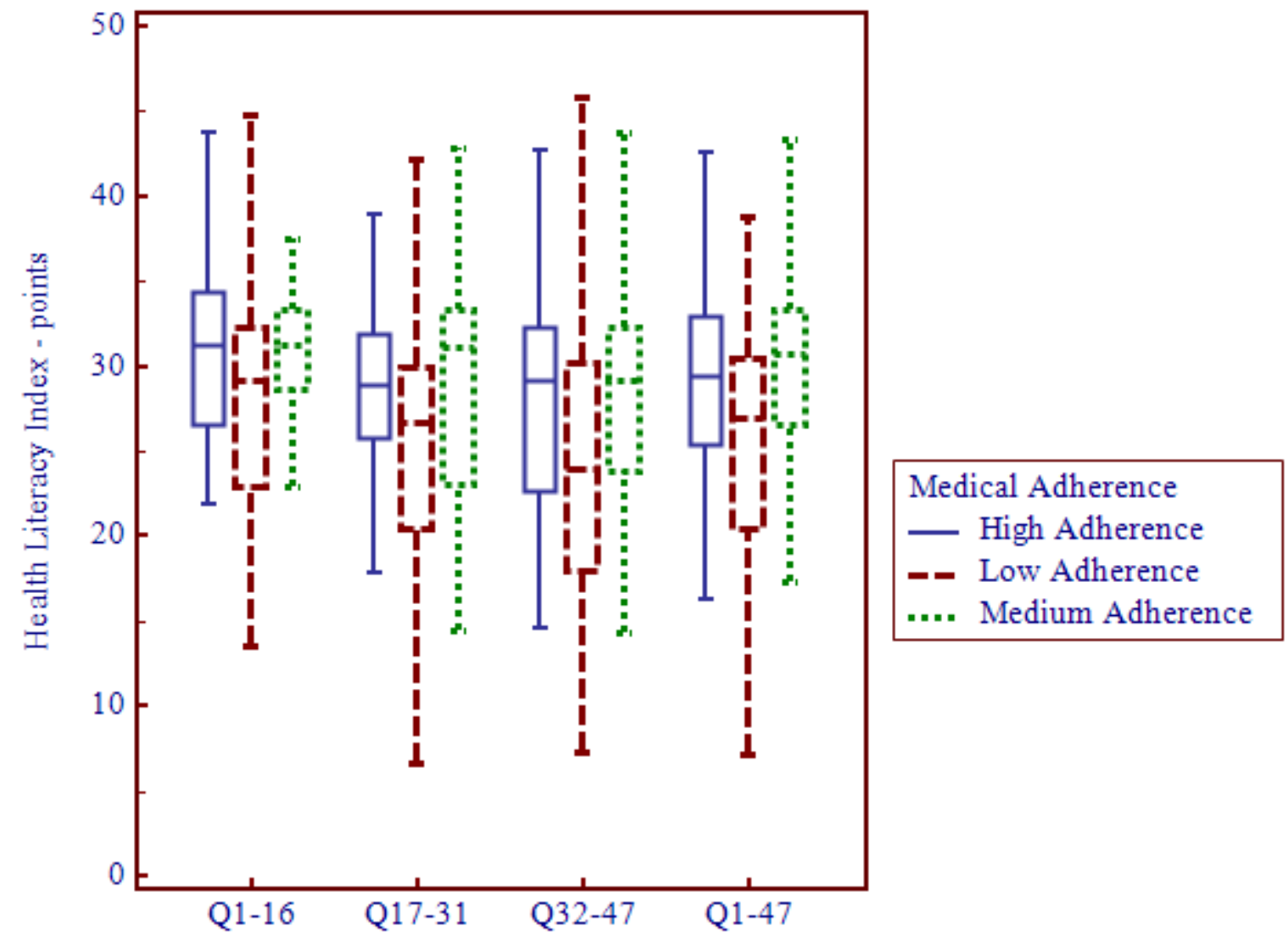

Figure1. Medication adherence to fibromyalgia drugs and health literacy 


\section{DISCUSSION}

Based on the results of our study, as HL increased among FMS patients, the MA of the patients also increased. The patients' FIQ results were significantly negatively associated with their $\mathrm{HL}$. There was also a negative relationship between the MA and the VAS pain status. There was no relationship between the distribution of drugs used in the treatment and health literacy.

Previous studies have reported that the Morisky 8-Item MA scale is reliable in chronic diseases such as hypertension, diabetes mellitus and COPD [30-33]. As a result of our study, we found that the scale was also reliable for FMS patients, another common chronic disease. In a study of hypertension patients, it has been reported that there is a relationship between Morisky 8-Item MA scores and blood pressure control [34]. Similarly, the Morisky 8-Item MA scale showed a negative correlation with the VAS scale that assessed the current pain status in the FMS patients.

The importance of $\mathrm{HL}$ is more and more understood each passing day [35]. HL is an important guide for survival and health expenditures. In the present study,

it was seen both that the HLS-EU-Q47 scale was reliable in FMS patients and that HL was associated with MA. The patients with high $\mathrm{HL}$ scores were cases that used their medicines more regularly and therefore responded better to treatment. Buchbinder et al. [36] investigated $\mathrm{HL}$ in rheumatoid arthritis patients and concluded that low $\mathrm{HL}$, which is considerable in patients with rheumatoid arthritis, may lead to difficulties for patients to understand the treatment or prescription-related instructions. Likewise, $\mathrm{HL}$ was investigated in patients with chronic pain, and it was found that pain severity was lower in people with high $\mathrm{HL}$, which led to the idea that it may be easier for patients with $\mathrm{HL}$ to cope with pain [37].
It is known that there is a negative correlation between pain and education level [37]. In the present study, we found a correlation between $\mathrm{HL}$ and the FIQ and VAS scores. Accordingly, as the patients' pain scores increased, $\mathrm{HL}$ decreased. The theory that pain is a primitive complaint is confirmed [38]. We are convinced that educating patients about their illnesses will have a positive impact on reducing their pain or on their efforts in this area.

The most commonly used treatments for the patients within the scope of the study were duloxetine and pregabalin. Combined uses were also the case. In the literature, there is information that a combined treatment with these drugs will provide a positive contribution, in addition to their individual use. Separate or combined uses are also recommended in the guidelines. In this sampling, no relationship was found between the drugs used by patients and $\mathrm{HL}$ or MA. There is literature suggesting that as $\mathrm{HL}$ increases, gravitating towards specific treatments increases $[16,39]$, but there was no correlation between the drugs used in this sample and the $\mathrm{HL}$ status.

Limitations: The most important limitation in this study was the fact that it was a single-centered study and that it had a low number of cases. However, the sample size was found to be sufficient in the power analysis that was conducted. However, due to the above limitations, we think that no generalizations can be made about the subject. Another limitation is that we included patients who had been taking medication for at least six months. It can be considered that the $\mathrm{HL}$ status and the MA of the patients who stopped or who were not using the medicine immediately after the diagnosis were low, but this was not evaluated in the present study.

In conclusion, the Morisky 8 Item MA scale is reliable in patients with FMS and is negatively correlated with 
the present pain sensation. The HLS-EU-Q47 scale is also reliable in fibromyalgia patients, and its results correlate in the same direction as the Morisky 8 Item MA scale results. We believe that educational programs for patients about FMS and increasing their MA and $\mathrm{HL}$ will positively affect their treatment outcomes.

\section{Conflict of interest}

The authors declare that they have no conflict of interest.

\section{References}

1. Clauw DJ (2009). Fibromyalgia: an overview. Am J Med. 122(12):3-13.

2. Sauer K, Kemper C, Glaeske G. (2011) Fibromyalgia syndrome: prevalence, pharmacological and non-pharmacological interventions in outpatient health care An analysis of statutory health insurance data. Joint Bone Spine 78:80-4.

3. Topbaş M, Çakırbay H, Güleç H, Akgöl E, Ak I, Can G. (2005) The prevalence of fibromyalgia in women aged 20-64 in Turkey. Scand J Rheumatol 34(2):140-4.

4. Bellato E, Marini E, Castoldi F, Barbasetti N, Mattei L, Bonasia DE, Bionna D. (2012) Fibromyalgia syndrome: etiology, pathogenesis, diagnosis, and treatment. Pain Res Treat 2012:426130.

5. Macfarlane GJ, Kronisch C, Dean LE, Atzeni F, Hauser W, Flub E, Choy E, Kosek E, Amris K, Branco J, Dincer F, Leino-Arjas P, Longley K, McCarhy GM, Makri S, Perrot S, Sarzi-Puttini P, Taylor A, Jones GT (2017). EULAR revised recommendations for management of fibromyalgia. Ann Rheum Dis 76(2):318-28.

6. Clauw D. (2014) Fibromyalgia: a clinical review JAMA 311(15):1547-55.

7. Berger A, Dukes $E$, Martin S, Edelsberg J, Oster G. (2007) Characteristics and healthcare costs of patients with fibromyalgia syndrome. Int Clin Prect 61:1498-1508.

8. Sorensen $K$, Van den Broucke $S$, Fullam J, Doyle G, Pelikan J, Slonska Z, Brand H: (HLSEU) Consortium Health Literacy Project European (2012) Health literacy and public health: A systematic review and integration of definitions and models. BMC Public Health $12: 80$

9. Cayci HM, Erdogdu UE, Demirci H, Ardic A, Topak N Y, Taymur İ (2017). Effect of Health Literacy on Help-seeking Behavior in Morbidly Obese Patients Agreeing to Bariatric Surgery. Obesity surgery 1-7.

10. Baker DW, Parker RM, Williams MV, Clark WS. (1998). Health literacy and the risk of hospital admission. Journal of general internal medicine, 13(12), 791-8.

11. Wolfe F, Anderson J, Harkness D, Bennett RM, Caro XJ, Goldenberg DL, Russell IJ, Yunus MB. (1997) A prospective, longitudinal, multicentre study of service utilization and costs in fibromyalgia. Arthritis \& Rheumatism 40:156070.

12. Hughes G, Martinez C, Myon E, Taieb C, Wessely S. (2006) The impact of a diagnosis of fibromyalgia on health care resource use by primary care patients in the UK: An observational study based on clinical practice. Arthritis \& Rheumatism 54,177-83.

13. Eichler K, Wieser S, Brügger U (2009). The costs of limited health literacy: a systematic review. International journal of public health, 54(5), 313.

14. Kripalani S, Yao X, Haynes RB (2007). Interventions to enhance medication adherence in chronic medical conditions: a systematic review. Archives of internal medicine, 167(6), 540-9.

15. Haynes RB, Ackloo E, Sahota N, McDonald HP, Yao X (2008). Interventions for enhancing medication adherence. The Cochrane Library.

16. Williams MV, Baker DW, Parker RM, Nurss JR (1998). Relationship of functional health literacy to patients' knowledge of their chronic disease: a study of patients with hypertension and diabetes. Archives of internal medicine, 158(2), 166-72.

17. Sadeghi S, Brooks D, Stagg-Peterson S, Goldstein R (2013). Growing awareness of the importance of health literacy in individuals with COPD. COPD.10(1):72-8.

18. Bains SS, Egede LE (2011). Associations between health literacy, diabetes knowledge, self-care behaviors, and glycemic control in a low income population with type 2 diabetes. Diabetes Technol Ther. (3);13(3):335-41. 
19. Al Sayah F, Majumdar SR, Johnson JA (2015). Association of Inadequate Health Literacy with Health Outcomes in Patients with Type 2 Diabetes and Depression: Secondary Analysis of a Controlled Trial. Can J Diabetes. (8);39(4):259-65.

20. Baker DW, Gazmararian JA, Sudano J, Patterson M. (2000). The association between age and health literacy among elderly persons. The Journals of Gerontology Series B: Psychological Sciences and Social Sciences, 55(6), 368-74.

21. Schillinger $D$, Grumbach $K$, Piette $J$, Wang $F$, Osmond D, Daher C, Palacious J, Sullivan GD, Bindman AB. (2002). Association of health literacy with diabetes outcomes. Jama, 288(4), 475-82.

22. Omachi TA, Sarkar U, Yelin EH, Blanc PD, Katz PP (2013). Lower health literacy is associated with poorer health status and outcomes in chronic obstructive pulmonary disease. Journal of general internal medicine, 28(1), 74-81.

23. Price $D D$, McGrath $P A$, Rafii $A$, Buckingham $B$ (1983). The validation of visual analogue scales as ratio scale measures for chronic and experimental pain. Pain 17:45-56.

24. Burckhardt CS, Clark SR, Bennett RM (1991). The Fibromiyalgia Impact Questionnaire: development and validation. J Rheumatol 18: 728-33.

25. Sarmer S, Ergin S, Yavuzer G (2000). The validity and reliability of the Turkish version of the Fibromyalgia Impact Questionnaire. Rheumatol Int 20: 9-12.

26. Durusu Tanriover M, Yıldırım HH, DemirayReady FN (2017). Turkiye sağlık okur-yazarlığı araştırması [Turkey health literacy survey]. Ankara: Sağlık-Sen.

27. Morisky DE, Green LW, Levine DM (1986). Concurrent and predictive validity of a selfreported measure of medication adherence. Medical care 67-74.

28. Aşılar RH, Gözüm S, Çapık C, Morisky DE (2014). Reliability and validity of the Turkish form of the eight-item Morisky medication adherence scale in hypertensive patients. Anatolian Journal of Cardiology/Anadolu Kardiyoloji Dergisi, 14(8).

29. Korb-Savoldelli V, Gillaizeau F, Pouchot J, Lenain E, Postel-Vinay N, Plouin PF, Durieux P, Sabatier B (2012). Validation of a French
Version of the 8-Item Morisky Medication Adherence Scale in Hypertensive adults. J Clin Hypertens (Greenwich). 14(7):429-34.

30. Rodriguez Martinez CE, Sossa MP, Rand CS (2007). Validation of a questionnaire for assessing adherence to metered-dose inhaler use in asthmatic children. Pediatr Allergy Immunol Pulmonol 20:243-53.

31. Kripalani S, Risser J, Gatti ME, Jacobson TA (2009). Development and evaluation of the Adherence to Refills and Medications Scale (ARMS) among low-literacy patients with chronic disease. Value Health 12:118-23.

32. Lambert EV, Steyn K, Stender S, Everage N, Fourie JM, Hill M (2006). Cross-cultural validation of the hill-bone compliance to high blood pressure therapy scale in a South African, primary healthcare setting. Ethn Dis. $16: 286-29$.

33. Wang $Y$, Lee J, Tang WE, Toh MP, Ko $Y$ (2012). Validity and reliability of a selfreported measure of medication adherence in patients with Type 2 diabetes mellitus in Singapore. Diabet Med. 29:338-344.

34. Nielsen J $\varnothing$, Shrestha AD, Neupane $D$, Kallestrup P (2017). Non-adherence to antihypertensive medication in low-and middleincome countries: a systematic review and meta-analysis of 92443 subjects. Journal of human hypertension 31(1), 14-21.

35. Berkman ND, Sheridan $\mathrm{SL}$, Donahue $\mathrm{KE}$, Halpern DJ, Crotty K (2011). Low health literacy and health outcomes: an updated systematic review. Annals of internal medicine 155(2), 97-107.

36. Buchbinder R, Hall S, Youd JM (2006). Functional health literacy of patients with rheumatoid arthritis attending a communitybased rheumatology practice. The Journal of rheumatology 33(5), 879-86.

37. Köppen PJ, Dorner TE, Stein KV, Simon J, Crevenna R (2017). Health literacy, pain intensity and pain perception in patients with chronic pain. Wiener klinische Wochenschrift, 1-8.

38. Holton R. (2015). Primitive Self-Ascription. A Companion to David Lewis, 57, 399.

39. Amalraj S, Starkweather C, Nguyen C. (2009). Health literacy, communication, and treatment decision-making in older cancer patients. Oncology, 23(4), 369. 